\title{
STUDY ON INTEGRATING APPLICATION METHOD FOR AD AND TRIZ
}

\author{
Zishun Chen, Runhua Tan \\ School of Mechanical Engineering, Hebei University of Technology, Tianjin, 300130, \\ China; Email:chenzishun@126.com.
}

\begin{abstract}
The AD and TRIZ are the important methods of conceptual design. A planeness measurement equipment is analyzed and the finding problems are solved through using the $A D$ and TRIZ. In order to satisfy the new requirements presented by production line to planeness measurement equipment, the redesign of planeness measurement equipment is carried out by using AD and TRIZ. The new conceptual design possesses many excellencies such as higher measurement efficiency, lower work strength etc., and satisfied the requirements of production line.
\end{abstract}

Key words: AD, TRIZ, Conceptual Design, Contradiction Matrix.

\section{INTRODUCTION}

For the manufacturing industry enterprises, the quality and efficiency of production line in manufacturing product is very important for competition in the current market. In order to control the varying tendency of product quality, it is a usually method that adopts special measurement equipments to carry out on-line measurement for work-piece of production line. However, in many small and medium-sized enterprises, there exist a problem that results in the time of measuring one work-piece is much longer than one manufacturing cycle when using on-line measurement equipments. Therefore the operation of work-piece measurement is a bottle-neck for the production line, which leads to not only not quickly to know the quality state of work-piece, but also affect the efficiency of production.

For the planeness measurement equipment of work-piece, the total time of measurement one work-piece includes adjusting work-piece position time and measuring time. But most of the time is for the adjusting work-piece

This project is supported by the National Natural Science Foundation of China under the grant No.50375045

Please use the following format when citing this chapter:

Chen, Zishun, Tan, Runhua, 2006, in International Federation for Information Processing (IFIP), Volume 207, Knowledge Enterprise: Intelligent Strategies In Product Design, Manufacturing, and Management, eds. K. Wang, Kovacs G., Wozny M., Fang M., (Boston: Springer), pp. 421-432. 
position, therefore, the problem is the main reason that affects the quality control and production efficiency.

In this paper, the Axiomatic Design (AD) ${ }^{[1,2]}$ and TRIZ theory ${ }^{[3]}$ are used to analyze and redesign the measurement equipment of work-piece planeness.

\section{THE IMPROVEMENT DESIGN OF PLANENESS SPECIAL MEASUREMENT EQUIPMENT}

In many small and medium-sized enterprises, the tools of measuring work-piece's planeness are usually standard plate, height gauge, support screw poles, and the measurement work is carried out by manual methods. Due to the measurement method possesses some excellencies such as simple in tool's structure, low cost, so it is used widely. When measuring the planeness of work-piece, the first step is to place three support screw poles (P1、P2 and P3) on the standard plate, and then place the work-piece on three support screw poles and lets the waiting measurement plane $\mathrm{A}$ face to up. Before using the height gauge to measure the plane $\mathrm{A}$, the position of work-piece must be adjusted, namely through adjusting P1、P2 and P3 of contacting with the bottom plane $B$ of work-piece, the three measurement benchmark points (M1, M2 and M3) on plane A have to be on the same height relative to the standard plane, as shown in Fig.1.

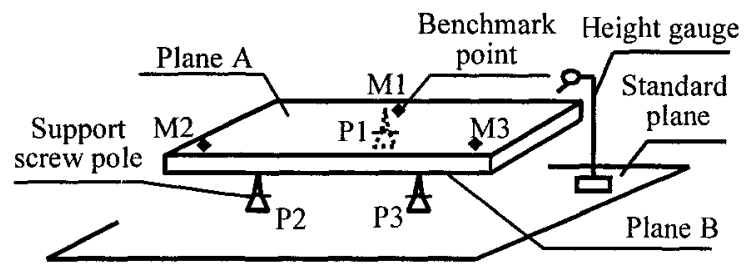

Figure 1 . The measurement method of planeness

\subsection{The problems description}

In order to cause the three benchmark points have the same heights by adjusting the plane $\mathrm{A}$, then need to adjust the three support screw poles. But because adjusts anyone vertical position of support screw pole, it will affect the vertical positions of three benchmark points simultaneously, thus must have to adjust the three support screw poles repeatedly, and result in the preparative time of adjusting workpiece's position occupies mostly the time of entire measurement process, so the efficiency of measurement is very low. 


\subsection{Using the $\mathrm{AD}$ to analyze the measurement equipment}

According to the $\mathrm{AD}$ theory, In order to obtain the leaf level FRs and DPs of hierarchy, the zigzagging mapping and decomposition must be carried out between the FRs and the DPs of upper level ${ }^{[2]}$.

On the level 1, the FRs, Cs and DPs of the planeness measurement equipment are described respectively as:

$F R_{0}$ : Measure the planeness of plane $\mathrm{A}$.

$\mathrm{C}_{11}$ : Speedily adjust the plane $\mathrm{A}$ to parallel with the standard plate.

$\mathrm{C}_{12}$ : Apply the manual adjustment equipment.

$D P_{0}$ : The measurement equipment of plane $\mathrm{A}$.

According to the $\mathrm{AD}$, the level 1 design equation can be expressed as:

$$
\left\{F R_{0}\right\}=[A]\left\{D P_{0}\right\}
$$

The FRs and DPs of level 2 are described as:

$F R_{1}$ : Adjust the vertical position of point $\mathrm{M} 1$ on the plane $\mathrm{A}$.

$F R_{2}$ : Adjust the vertical position of point M2 on the plane A.

$F R_{3}$ : Adjust the vertical position of point M3 on the plane A.

$\mathrm{C}_{21}$ : In order to enhance measurement precision, the benchmark points $\mathrm{M} 1, \mathrm{M} 2$ and M3 must be dispersed and closed the brim of plane A.

$\mathrm{C}_{22}$ : The three support screw poles (P1、P2 and P3) can be moved only in the area F, as shown in Fig.2.

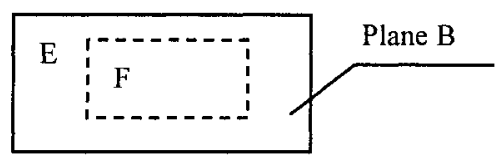

Figure 2. The situation of plane B

$D P_{1}$ : Using support screw pole $\mathrm{P} 1$ of contacting with plane $\mathrm{B}$.

$D P_{2}$ : Using support screw pole $\mathrm{P} 2$ of contacting with plane $\mathrm{B}$.

$D P_{3}$ : Using support screw pole $\mathrm{P} 3$ of contacting with plane $\mathrm{B}$.

The design equation of level 2 can be written as:

$$
\left\{\begin{array}{l}
F R_{1} \\
F R_{2} \\
F R_{3}
\end{array}\right\}=\left[\begin{array}{lll}
A_{11} & A_{12} & A_{13} \\
A_{21} & A_{22} & A_{23} \\
A_{31} & A_{32} & A_{33}
\end{array}\right]\left\{\begin{array}{l}
D P_{1} \\
D P_{2} \\
D P_{3}
\end{array}\right\}
$$

For equation (2), the design matrix [A] can be expressed as: 


$$
[A]=\left[\begin{array}{lll}
A_{11} & A_{12} & A_{13} \\
A_{21} & A_{22} & A_{23} \\
A_{31} & A_{32} & A_{33}
\end{array}\right]
$$

When using the measurement equipment to measure workpiece, the relations between positions of three measurement benchmark points of plane $\mathrm{A}$ and the positions of three support screw poles of contacting with plane B are shown in Fig.3. In Fig.3, the letter symbols are indicated as:

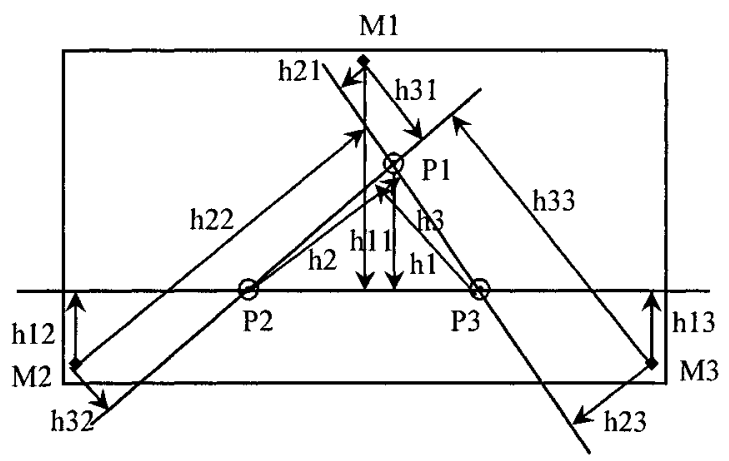

Figure 3. The position relations of three benchmark points and three support screw poles

$h_{1}$ is the distance of $\mathrm{P} 1$ reaching the $\mathrm{P} 2$ and $\mathrm{P} 3$ line.

$h_{2}$ is the distance of $\mathrm{P} 2$ reaching the $\mathrm{P} 1$ and $\mathrm{P} 3$ line.

$h_{3}$ is the distance of $\mathrm{P} 3$ reaching the $\mathrm{P} 1$ and $\mathrm{P} 2$ line.

$h_{11}, h_{12}$ and $h_{13}$ are the distances of benchmark points M1, M2 and M3 reaching $\mathrm{P} 2$ and $\mathrm{P} 3$ line respectively when adjust the support screw pole $\mathrm{P} 1$.

$h_{21}, h_{22}$ and $h_{23}$ are the distances of benchmark points M1, M2 and M3 reaching $\mathrm{P} 1$ and $\mathrm{P} 3$ line respectively when adjust the support screw pole $\mathrm{P} 2$.

$h_{31}, h_{32}$ and $h_{33}$ are the distances of benchmark points M1, M2 and M3 reaching $\mathrm{P} 1$ and $\mathrm{P} 2$ line respectively when adjust the support screw pole $\mathrm{P} 3$.

According to the design matrix's elements formula $A_{\mathrm{ij}}=\partial F R_{\mathrm{i}} / \partial F R_{\mathrm{j}}{ }^{[2]}$, the elements of design matrix $[A]$ may be determined as:

$$
\begin{array}{ccc}
A_{11}=h_{11} / h_{1} & A_{12}=-h_{21} / h_{2} & A_{13}=-h_{31} / h_{3} \\
A_{21}=-h_{12} / h_{1} & A_{22}=h_{22} / h_{2} & A_{23}=-h_{23} / h_{3} \\
A_{31}=-h_{13} / h_{1} & A_{32}=-h_{23} / h_{2} & A_{33}=h_{33} / h_{3}
\end{array}
$$

In terms of the design matrix's elements above, the design equation of level 2 can be expressed as: 


$$
\left\{\begin{array}{l}
F R_{1} \\
F R_{2} \\
F R_{3}
\end{array}\right\}=\left[\begin{array}{ccc}
h_{11} / h_{1} & -h_{21} / h_{2} & -h_{31} / h_{3} \\
-h_{12} / h_{1} & h_{22} / h_{2} & -h_{32} / h_{3} \\
-h_{13} / h_{1} & -h_{23} / h_{2} & h_{33} / h_{3}
\end{array}\right]\left\{\begin{array}{l}
D P_{1} \\
D P_{2} \\
D P_{3}
\end{array}\right\}
$$

Because the design matrix's elements $A_{\mathrm{ij}}$ of design equation (4) are all nonzero elements, so that the design of level 2 is a coupled design, it does not satisfy the independence axiom ${ }^{[1,2]}$ and need to decouple.

\subsection{The coupled design of measurement equipment decoupling and improvement}

For the design matrix's elements $\mathrm{A}_{\mathrm{ij}}$ of equations (2), if lets the $A_{\mathrm{ij}}=0$ except $\mathrm{i}=\mathrm{j}$, namely $h_{12}=h_{13}=h_{21}=h_{23}=h_{31}=h_{32}=0$, then the design matrix $[A]$ is become a diagonal matrix, and satisfies the independence axiom. For this example, i.e. must lets the positions of three support screw poles superposing with the positions of three benchmark points respectively.

Due to the design of measurement equipment exists $\mathrm{C}_{21}$ and $\mathrm{C}_{22}$, so these positions can not be superposed between the three support screw poles and the three benchmark points, which exists a contradiction in the decoupling process. For the coupled design can not be decoupled directly, therefore it needs to use the TRIZ to eliminate the contradiction.

Because exists a contradiction, so causes the positions of three measurement benchmark points can not be adjusted one to one with three support screw poles, and results in adjusting repeatedly and need a long time. Thus the first characteristic is described as 'Loss of time' by using 39 characteristics of TRIZ ${ }^{[4]}$. The distributive positions of support screw poles are restricted by $\mathrm{C}_{22}$, and then using the 39 characteristics to describe the second characteristic is 'Length of a stationary object'. Because the contradiction relates to two different characteristics, so the contradiction belongs to technical contradiction ${ }^{[S]}$.

For solving this technical contradiction, the inventive principles No.30, 24,14 and 5 can be obtained by using the contradiction matrix ${ }^{[6,7]}$ of TRIZ. Though analyzing, the inventive principle No. 24 can be used, namely No.24 is a principle solution. The content of No. 24 is 'Mediator'.

In this real example, the 'Mediator' is a piece of segregation plate, and placed between three support screw poles and plane B when the workpiece is measured. Thus the distributive positions of three support screw poles can be superposed with three benchmark points (here $A_{11}=A_{22}=A_{33}=1$ ), and the area $\mathrm{E}$ of plane B can not be destroyed simultaneously, as shown in Fig.4.

The additive segregation plate is a field solution of using the principle solution 'Mediator'. In the scheme of improving design, when adjusts the vertical position of anyone support screw pole, then only affects the vertical 


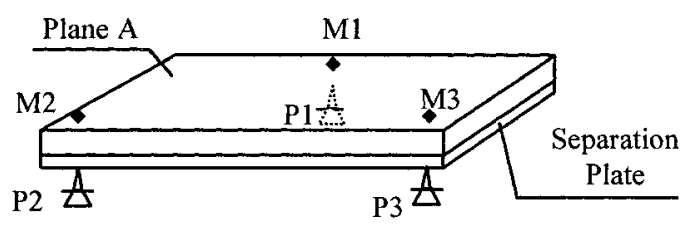

Figure 4. The conceptual design of measurement equipment after improving

position of corresponding measurement benchmark point, therefore the time of adjusting workpiece's position can be shortened.

The improving design of the measurement equipment is an uncoupled design, and the design equation is written as:

$$
\left\{\begin{array}{l}
F R_{1} \\
F R_{2} \\
F R_{3}
\end{array}\right\}=\left[\begin{array}{lll}
1 & 0 & 0 \\
0 & 1 & 0 \\
0 & 0 & 1
\end{array}\right]\left\{\begin{array}{l}
D P_{1} \\
D P_{2} \\
D P_{3}
\end{array}\right\}
$$

\section{THE NEW DESIGN OF SPECIAL PLANENESS MEASUREMENT EQUIPMENT}

When measures the workpiece, because the work of putting in and taking out the workpiece from measurement equipment is performed by manpower, so the planeness measurement equipment improved design above is suitable for the production line that only produces pint-sized or light weight products. But for the production line that produces the good-sized or heavier workpieces, it will cause the inspector to be borne heavy load and the measurement time will be protracted. So the measurement equipment improved must be redesign in order that the measurement equipment suitable for heavy workpiece production line.

\subsection{The framework model of new planeness measurement equipment}

Conveying the heavy workpieces when measurement is not suitable for manpower. Therefore, there is a contradiction between the operation method of using measurement equipment improved and the design constraint that for the heavier workpiece must avoid conveying by manpower, and this contradiction can be described by 39 characteristics of TRIZ as:

The worsening characteristic is No. 2: 'weight of a stationary object';

The improving characteristic is No. 37: 'difficulty of detecting and measuring'. 
Clearly the contradiction belongs to a technical contradiction, and can obtain 4 commending inventive principles from contradiction matrix, i.e. No.6, 13, 28 and 1.The inventive principles No.13 and No.1 can be used by analyzing. The content of inventive principle No.13 is 'The other way round', and the content of inventive principle No.1 is 'Segmentation'.

For this real example, the principle solution No.13 'The other way round' can be understood and described as: when measures the planeness of workpiece, the operational method is to convey the measurement equipment instead of workpiece; the principle solution No.1 'Segmentation' can be described as: when measure the workpiece' planeness, the measuring tool is a multi-gauge system instead of a height gauge.

According to the inventive principles No.13 and No.1, the framework model of new planeness measurement equipment can be illustrated in Fig.5.

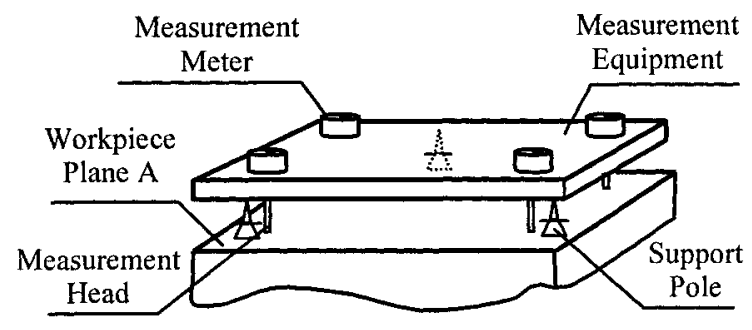

Figure 5. The framework model of planeness measurement equipment

\subsection{Describing for the FRs, Cs and DPs of new measurement equipment}

In order to suit the production line of producing good-sized or heavy weight workpiece, the FRs, Cs and DPs of measurement equipment need to redefine and need decompose between FRs and DPs.

At level 1, the FRs, Cs and corresponding DPs are expressed as:

$F R_{1}$ : Measure the planeness of plane A.

$F R_{2}$ : Measurement process can be carried out advantageously.

$\mathrm{C}_{11}$ : Use the manual method to measure workpiece.

$\mathrm{C}_{12}$ : Only convey the measurement equipment.

$\mathrm{C}_{13}$ : The work strength is low in measurement process.

$D P_{1}$ : Using the special planeness measurement equipment.

$D P_{2}$ : Using the maneuverable special measurement equipment.

According to the $\mathrm{AD}$ theory, the design equation of level 1 is:

$$
\left\{\begin{array}{l}
F R_{1} \\
F R_{2}
\end{array}\right\}=\left[\begin{array}{ll}
\mathrm{x} & 0 \\
0 & \mathrm{x}
\end{array}\right]\left\{\begin{array}{l}
D P_{1} \\
D P_{2}
\end{array}\right\}
$$


At level 2, the FRs, Cs and corresponding DPs are expressed as:

$F R_{11}$ : According to the shape and size of plane A determine the quantity and position of collecting measurement data.

$F R_{12}$ : The structure of measurement equipment possesses high stability.

$F R_{21}$ : Obtain the measurement data easily.

$F R_{22}$ : Calibrate the measurement equipment easily.

$F R_{23}$ : Convey the measurement equipment easily.

Cs: Equal to $\mathrm{C}_{11}, \mathrm{C}_{12}$ and $\mathrm{C}_{13}$.

$D P_{11}$ : The measurement equipment that distributes the measurement points reasonably at the proper positions of plane A.

$D P_{12}$ : Using the rigid structure to prevent distortion.

$D P_{21}$ : The measurement equipment can display measurement data.

$D P_{22}$ : Special calibration device.

$D P_{23}$ : Using a pair of handles structure.

The design equation of level 2 is:

$$
\begin{gathered}
\left\{\begin{array}{l}
F R_{11} \\
F R_{12}
\end{array}\right\}=\left[\begin{array}{ll}
\mathrm{x} & 0 \\
0 & \mathrm{x}
\end{array}\right]\left\{\begin{array}{l}
D P_{11} \\
D P_{12}
\end{array}\right\} \\
\left\{\begin{array}{l}
F R_{21} \\
F R_{22} \\
F R_{23}
\end{array}\right\}=\left[\begin{array}{lll}
\mathrm{x} & 0 & 0 \\
0 & \mathrm{x} & 0 \\
0 & 0 & \mathrm{x}
\end{array}\right]\left\{\begin{array}{l}
D P_{21} \\
D P_{22} \\
D P_{23}
\end{array}\right\}
\end{gathered}
$$

At level 3, the FRs, Cs and corresponding DPs are expresses as (in here hypothesize the new measurement equipment distributing 10 waiting measurement points on the reasonable positions of plane A):

$F R_{1101}$ : Collect the measurement data at reasonable position 1.

$F R_{1102}$ : Collect the measurement data at reasonable position 2 .

$F R_{1110}$ : Collect the measurement data at reasonable position 10 .

Cs: Equal to $\mathrm{C}_{11}, \mathrm{C}_{12}$ and $\mathrm{C}_{13}$.

$D P_{1101}$ : Installing a special meter to display measuring data at position 1 .

$D P_{1102}$ : Installing a special meter to display measuring data at position 2 .

$D P_{1110}$ : Installing a special meter to display measuring data at position 10 .

Through decomposing $F R_{11}$ and $D P_{11}$, the design equation can be expressed as: 


$$
\left\{\begin{array}{l}
F R_{1101} \\
F R_{1102} \\
F R_{1103} \\
F R_{1104} \\
F R_{1105} \\
F R_{1106} \\
F R_{1107} \\
F R_{1108} \\
F R_{1109} \\
F R_{1110}
\end{array}\right\}=\left[\begin{array}{llllllllll}
\mathrm{x} & 0 & 0 & 0 & 0 & 0 & 0 & 0 & 0 & 0 \\
0 & \mathrm{x} & 0 & 0 & 0 & 0 & 0 & 0 & 0 & 0 \\
0 & 0 & \mathrm{x} & 0 & 0 & 0 & 0 & 0 & 0 & 0 \\
0 & 0 & 0 & \mathrm{x} & 0 & 0 & 0 & 0 & 0 & 0 \\
0 & 0 & 0 & 0 & \mathrm{x} & 0 & 0 & 0 & 0 & 0 \\
0 & 0 & 0 & 0 & 0 & \mathrm{x} & 0 & 0 & 0 & 0 \\
0 & 0 & 0 & 0 & 0 & 0 & \mathrm{x} & 0 & 0 & 0 \\
0 & 0 & 0 & 0 & 0 & 0 & 0 & \mathrm{x} & 0 & 0 \\
0 & 0 & 0 & 0 & 0 & 0 & 0 & 0 & \mathrm{x} & 0 \\
0 & 0 & 0 & 0 & 0 & 0 & 0 & 0 & 0 & \mathrm{x}
\end{array}\right]\left\{\begin{array}{l}
D P_{1101} \\
D P_{1102} \\
D P_{1103} \\
D P_{1104} \\
D P_{1105} \\
D P_{1106} \\
D P_{1107} \\
D P_{1108} \\
D P_{1109} \\
D P_{1110}
\end{array}\right\}
$$

The results of decomposing $F R_{12}$ and $D P_{12}$ are as:

$F R_{121}$ : The main body of measurement equipment has no distortion.

$F R_{122}$ : When measure, the measurement equipment's position keep invariability relative to the plane A

$F R_{123}$ : Can install the measuring meters.

$D P_{121}$ : The main body of measurement equipment can be made of high strength material as carbon steel or aluminium alloy etc.

$D P_{122}$ : Using three rigid and fixed support poles.

$D P_{123}$ : Using the structure that can install the measuring meters.

By decomposing $F R_{12}$ and $D P_{12}$, the design equation can be obtained:

$$
\left\{\begin{array}{l}
F R_{121} \\
F R_{122} \\
F R_{123}
\end{array}\right\}=\left[\begin{array}{lll}
\mathrm{x} & 0 & 0 \\
0 & \mathrm{x} & 0 \\
0 & 0 & \mathrm{x}
\end{array}\right]\left\{\begin{array}{l}
D P_{121} \\
D P_{122} \\
D P_{123}
\end{array}\right\}
$$

The results of decomposing $F R_{21}$ and $D P_{21}$ are as:

$F R_{211}$ : Can display the measurement data.

$F R_{212}$ : Can read the measurement data easily.

$D P_{211}$ : Special measuring meters.

$D P_{212}$ : The dial of measurement meter face to up (see Fig.6).

By decomposing $F R_{21}$ and $D P_{21}$, the design equation is expressed as:

$$
\left\{\begin{array}{l}
F R_{211} \\
F R_{212}
\end{array}\right\}=\left[\begin{array}{ll}
\mathrm{x} & 0 \\
0 & \mathrm{x}
\end{array}\right]\left\{\begin{array}{l}
D P_{211} \\
D P_{212}
\end{array}\right\}
$$

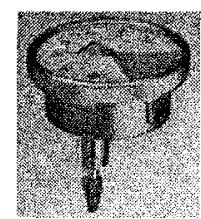

Figure 6. Special measuring meter

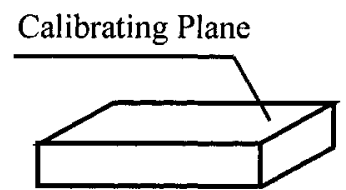

Figure 7. The calibrating plate 
Using the same method to decompose the $F R_{22}$ and $D P_{22}$ as:

$F R_{221}$ : Can provide the benchmark data.

$F R_{222}$ : The 10 measuring meters can be calibrated synchronously.

$D P_{221}$ : Using the calibrating plate (see Fig.7).

$D P_{222}$ : The calibrating plane that possesses proper shape and size.

Via decomposing $F R_{22}$ and $D P_{22}$, the design equation is expressed as:

$$
\left\{\begin{array}{l}
F R_{221} \\
F R_{222}
\end{array}\right\}=\left[\begin{array}{ll}
\mathrm{x} & 0 \\
0 & \mathrm{x}
\end{array}\right]\left\{\begin{array}{l}
D P_{221} \\
D P_{222}
\end{array}\right\}
$$

Because of the $F R_{23}$ and $D P_{23}$ are at the leaf level already through decomposing above, so they will not be decomposed continually.

The function of calibrating plate is to calibrate 10 measuring meters synchronously before measuring planeness of plane A. The process of measurement planeness is first putting the measurement equipment on the calibrating plane to regulate the 10 meters 'zero', then places the calibrated measurement equipment on the plane $\mathrm{A}$ of workpiece, the maximum difference value of the showing data of 10 measuring meters is the planeness value of plane $A$.

The new conceptual design of measurement equipment has 18 leaf level FRs and 18 leaf level DPs through decomposing. The corresponding relations of these leaf level FRs and DPs are shown in Table 1.

Table 1 . The relations of leaf level FRs and leaf level DPs.

\begin{tabular}{|c|c|c|c|c|c|c|c|c|c|c|c|c|c|c|c|c|c|c|}
\hline & 㤩 & 穿 & 学 & 鸹 & 总 & 号 & 点 & 总 & 奇 & 总 & $\overrightarrow{\overrightarrow{3}}$ & 홈 & $\underset{⿱ 宀}{\stackrel{a}{口}}$ & 紾 & 荵 & 芯 & 空 & 芯 \\
\hline 21101 & & & & 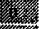 & 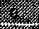 & (6) & t) & tris & $\sqrt{3}$ & (x) & $0^{2}$ & 0 & a & 0 & 0 & $a$ & 0 & 0 \\
\hline 21102 & & & & (3) & 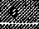 & $x^{2}=$ & (2) & (3) & ty & - & $0^{1}$ & 0 & 0 & 0 & 0 & o & 0 & 0 \\
\hline 1103 & & 楼 & 4 & 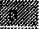 & 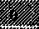 & 㮦衫 & Sy & 6) & 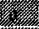 & , & $a^{1}$ & 0 & $\mathrm{a}$ & 0 & 0 & e & a & a \\
\hline 1104 & 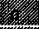 & 致 & tzes & s) & 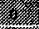 & 2) & very & (3) & 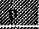 & (2) & $\mathbf{0}^{\mathbf{1}}$ & 0 & 0 & 0 & 0 & 0 & e & $\stackrel{0}{-}$ \\
\hline 1105 & text & 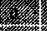 & 3. & r. & $\%$ & . & $x=$ & 6 & x & $5=0$ & $a^{1}$ & & a & 0 & 0 & $\stackrel{a}{a}$ & 0 & $a$ \\
\hline$R 1106$ & S & 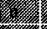 & \% & 2. & 6 & S & - = & 4 & re & 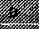 & $\mathbf{0}^{\mathbf{1}}$ & 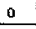 & a & 0 & 0 & 0 & $a$ & a \\
\hline$R 110\}$ & 垁 & 玨 & $x=$ & 3) & C) & (x) & \% & (6) & (x) & \% & $0^{2}$ & $\underline{0}$ & 0 & 0 & 0 & 0 & o & 0 \\
\hline R.108 & & Y & X & 程 & Hen & (x) & X) & m & 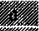 & 筷) & $a^{2}$ & 0 & $a$ & 0 & 0 & 0 & 0 & $a$ \\
\hline FR1109 & - & S6 & W & Y) & (3) & (2) & teres & \% & 药的 & try & $a^{1}$ & $\bar{a}$ & 0 & 0 & 0 & 0 & o & 0 \\
\hline FR1110 & 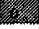 & 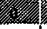 & the & X) & (6) & 2. & 2m & 经) & (3) & 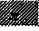 & $0^{1}$ & 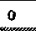 & $a$ & 0 & 0 & 0 & 0 & 0 \\
\hline FR121 & 0 & I & 0 & 0 & a & 0 & 0 & $a$ & 0 & 0 & S & 柆 & (x) & 0 & $a$ & 0 & 0 & 0 \\
\hline FR.122 & 0 & 0 & 0 & 0 & o & 0 & 0 & 0 & c & o & 1 & $5=$ & \% & 0 & 0 & 0 & 0 & 0 \\
\hline & 0 & 0 & 0 & 0 & 0 & 0 & 0 & a & 0 & o & X) & . & tzex & 0 & 0 & 0 & 0 & 0 \\
\hline & 0 & o & 0 & 0 & o & 0 & 0 & $\underline{0}$ & & a & 0 & 0 & $a$ & 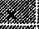 & $x^{2} g$ & 0 & 0 & 0 \\
\hline & o & 0 & a & 0 & 0 & 0 & 0 & 0 & 0 & a & 0 & 0 & $a$ & ret. & 3) & 0 & 0 & 0 \\
\hline & o & 0 & a & o & 0 & 0 & a & $\underline{0}$ & 0 & o & 0 & $\underline{0}$ & $\underline{0}$ & 0 & 0 & & S & 0 \\
\hline 42 & $0^{-1}$ & $0^{2}$ & $0^{-}$ & $0^{-2}$ & $0^{2}$ & $0^{2}$ & $0^{2}$ & $0=$ & $0^{2}$ & $a^{2}$ & 0 & & 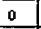 & & 0 & 絾 & 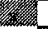 & 0 \\
\hline 22 & 0 & 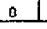 & $\underline{0}$ & & & & & & & & 0 & & $\underline{\underline{a}}$ & & u. & $\underline{v}$ & 0 & \\
\hline
\end{tabular}

Note:

1. The design of measurement equipment's rigidity should be carried out after the positions and assembly structure of 10 measurement meters were determined.

2. Before determining the shape and size of calibrating plate, the installing positions of 10 meters on measurement equipment body must be considered. 
In the Table 1, the shadow parts indicate the corresponding relations of the leaf level FRs and leaf level DPs that obtained from the same one design equation; no shadow parts indicate the corresponding relations of the leaf level FRs and leaf level DPs that obtained from the different design equations. If there exist correlations between the leaf level FRs and leaf level DPs in the no shadow parts, then the existing correlations can be considered as design constraints ${ }^{[2]}$.

For measuring heavy weight or good-sized workpiece, in order to assure measurement precision, measurement time and decrease work strength, on the foundation of original design, several new FRs and Cs are added, and a new conceptual design of measurement equipment is obtained.

The added FRs and $\mathrm{Cs}$ in the new conceptual design are as:

$\mathrm{FR}_{2}$ : Measurement process can be carried out advantageously.

$\mathrm{C}_{12}$ : Only convey the measurement equipment.

$\mathrm{C}_{13}$ : The work strength is low in measurement process.

The new conceptual design of measurement equipment is illustrated in Fig.8, and its characteristics are:

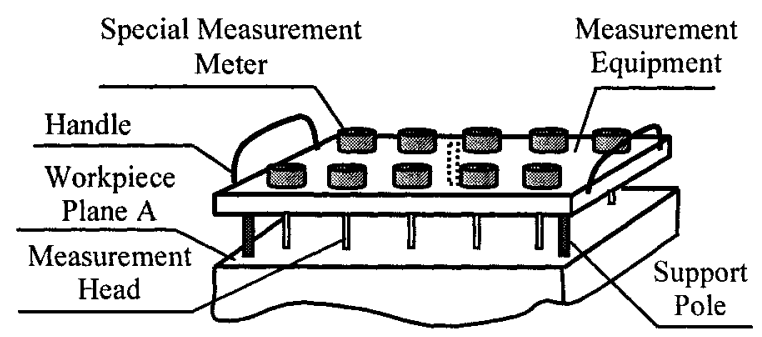

Figure 8 . The new conceptual design of measurement equipment

(1) The measurement process is rapid and the efficiency high.

The new measurement equipment is a multi-meters device that may measure many points on the plane A synchronously.

(2) To calibrate the 10 meters is easy.

When calibrating the 10 meters of measurement equipment to 'zero', it only need one time through using the calibrating plate.

(3) The strength of measurement work is low.

In the phase of detail design, the measurement equipment's designing must satisfy the requirement of proper weight.

(4) The Applying scope is wide.

The new measurement equipment is not only suited for measuring the planeness of heavy weight workpiece, but also for measuring the planeness of light weight workpiece. The new conceptual design of measurement equipment is an uncoupled design, which solved the bottle-neck problem of measurement process as well as satisfied the requirements of production line. 


\section{CONCLUSION}

(1) The AD and TRIZ are important methods for conceptual design. Using the design equations of $\mathrm{AD}$ can survey the conceptual design whether existing 'coupling' problem or not, so the $\mathrm{AD}$ can make the designer rationally judge the design, and provides a powerful tool for designer to find the good design.

The TRIZ provides an effective tool for designer to solve the contradictions of design process, and designer can obtain the anticipant design quickly by using the TRIZ to solve the coupling problems in AD process. So the powerful design method is formed by integrating the $A D$ and TRIZ.

(2) An improved design of workpiece planeness measurement equipment is carried out by using the $\mathrm{AD}$ and TRIZ. In order to expand the applying scope of measurement equipment, the contradictions among the new FRs, Cs and DPs must be solved. A new conceptual design of measurement equipment is obtained by using the $\mathrm{AD}$ and TRIZ and can Satisfy the requirements of production line.

\section{REFERENCES}

1. Nam P. Suh, The Principles of Design (Oxford University Press, 1990).

2. Nam P. Suh, Axiomatic Design-Advances And Applications (Oxford University Press, 2001)

3. Tan runhua, The Innovation Design (Mechanical Industrial of china Press, 2002).

4. Ellen Domb, Joe Miller, Ellen MacGran, and Michael Slocum (1998/11); http://www.triz-joumal.com/archives/

5. Michael S. Slocum, K.O.St.I., Ellen Domb, Catherine Lundberg (2003/01); http://www.triz-journal.com/archives/

6. Zinovy Royzen (1996/11); http://members.aol.com:/zroyzen/triz.html

7. Todd Williams, Ellen Domb (1998/05); http://www.triz-journal.com/archives/ 